\title{
Differential crosstalk between the AMPK and PI3K/Akt pathways in breast cancer cells of differing genotypes: Leptin inhibits the effectiveness of AMPK activation
}

\author{
OMAR S. EL-MASRY ${ }^{1-3}$, KALTOOM AL-SAKKAF ${ }^{4}$, BARRY L. BROWN ${ }^{1}$ and PAULINE R.M. DOBSON ${ }^{1}$ \\ ${ }^{1}$ Department of Human Metabolism, The Medical School, University of Sheffield, Sheffield, S10 2RX, UK
}

Received June 16, 2015; Accepted July 20, 2015

DOI: $10.3892 / o r .2015 .4198$

\begin{abstract}
AMP-activated protein kinase (AMPK), a sensor of cellular energy, is widely reported as a potential therapeutic target in treatment of breast and other cancers. The activated enzyme has been shown to be a promising anti-proliferative agent in breast cancer cell lines. However, little data exist on crosstalk between AMPK and the cellular survival axis of $\mathrm{PI} 3 \mathrm{~K} / \mathrm{Akt} / \mathrm{mTOR}$ pathway and the impact of microenvironment on cellular responses to AMPK activation. We present results which show differential crosstalk between AMPK and Akt, dependent on the cellular genetics of each breast cancer cell type. We also show that leptin blocks activation of AMPK and partially or completely attenuates the anti-proliferative effect of AMPK activation depending on the cell type. This suggests that leptin within the local environment might impose limitations on therapeutic usage of AMPK activators in cancer, thereby attenuating their effective use in many obese subjects.
\end{abstract}

\section{Introduction}

AMP-activated protein kinase (AMPK) is a pleiotropic enzyme playing a role in the control of numerous functions both centrally and peripherally (1). AMPK has now emerged as a potential therapeutic target for cancer as a consequence of being a substrate and a mediator of the tumour suppressor gene LKB1 (2). The tumour suppressing effects associated

Correspondence to: Dr Pauline R.M. Dobson, Department of Human Metabolism, The Medical School, University of Sheffield, Beech Hill Road, Sheffield, S10 2RX, UK

E-mail: p.dobson@sheffield.ac.uk

Present addresses: ${ }^{2}$ Department of Applied Medical Chemistry, Medical Research Institute, University of Alexandria, Alexandria 21561, Egypt; ${ }^{3}$ Department of Clinical Laboratory Sciences, College of Applied Medical Sciences, University of Dammam, Dammam 31441, Rakkah, Saudi Arabia; ${ }^{4}$ Department of Medical Laboratory Technology, Faculty of Applied Medical Sciences, King Abdulaziz University, Jeddah 21589, Saudi Arabia

Key words: leptin, breast cancer, AMP-activated protein kinase, Akt with AMPK activation include the ability of the enzyme to repress the lipogenic enzymes, fatty acid synthase and acetyl coA carboxylase (both enzymes are upregulated in cancer cells), to inhibit Akt phosphorylation and to phosphorylate p53 and p21, thereby triggering apoptotic and cell cycle arresting signals. Protein kinase B (PKB), also known as Akt, is a serine threonine kinase which belongs to the same family of protein kinases A, G and C (AGC family). Three human isoforms have been identified ( $\mathrm{PKB} \alpha$ or $\mathrm{Akt} 1, \mathrm{PKB} \beta /$ Akt 2 and $\mathrm{PKB} \gamma$ or Akt3). Akt influences several biological functions including metabolism, growth and proliferation by phosphorylating and modulating the activity of numerous cellular substrates, such as glycogen synthase kinase 3 , the mammalian target of rapamycin (mTOR), breast cancer susceptibility gene 1 (BRCA1) and others (3). Understanding the molecular mechanism of action and regulation of this enzyme is crucial as a result of its aberrant regulation in life-threatening disorders, such as cancer (4). Akt is activated downstream of phosphatidyl inositol 3-kinase (PI3K), which is activated upon interaction of growth factors with their receptors $(5,6)$. Akt isoform specific upregulation in various types of human cancers has been reported. Increased expression of AKT1 was reported in gastric cancers (7), while AKT2 has been reported to be amplified in ovarian carcinomas (8) and cancers of pancreas (9) and AKT3 in cancerous melanocytes (10). Akt1 has been reportedly activated in breast cancer (11), Akt2 in hepatic (12) and colorectal (13) cancers and finally, Akt3 is upregulated in ER-negative breast cancers (14). The involvement of both AMPK and Akt in metabolic and survival control suggests that, in cancer, there is crosstalk between Akt and AMPK. This study has been undertaken to investigate the effect of AMPK activation on Akt, phosphorylation and Akt inhibition on AMPK phosphorylation and proliferation in three human breast cancer cell lines each with differing genetic backgrounds. The adipose tissue-related hormone, leptin, is encoded by the $\mathrm{Ob}$ (obese) gene (7q31). Leptin is a pleiotropic hormone having numerous peripheral and central effects $(15,16)$. Leptin is an angiogenic, mitogenic and survival factor and is also an important metabolic regulator (17). Leptin binds to OB-R receptor and activates the JAK/STAT signalling pathway, which in turn activates MAPK and PI3K/Akt signalling pathways. So in addition, the effect of leptin on AMPK phosphorylation and on cell proliferation was also investigated. 


\section{Materials and methods}

5-aminoimidazole carboxamide ribonucleotide (AICAR) was from Sigma-Aldrich, Poole, Dorset, UK. InSolution ${ }^{\mathrm{TM}}$ Akt Inhibitor VIII (Isozyme-Selective, Akt-1/2), was purchased from Calbiochem ${ }^{\circledast}$, Watford, UK. Dulbecco's minimal essential medium (DMEM) was obtained from Gibco BRL, Paisley, UK and fetal calf serum (FCS) was from Autogenbioclean, UK Ltd. Phosphate-buffered saline and trypsin/EDTA were obtained from Sigma-Aldrich, Irvine, Ayrshire, UK. CellTiter $96^{\circledR}$ Aqueous One Solution cell proliferation assay was purchased from Promega, Madison, WI, USA. T25 and T75 tissue culture flasks were from Nunc ${ }^{\mathrm{TM}}$, Denmark and tissue culture sterile 6-, 24- and 96-well plates were from Costar ${ }^{\circledR}$, USA. Anti-phospho-AMPK (Thr172) and anti-phospho-Akt (Ser473) antibodies were purchased from Cell Signaling Technology; Danvers, MA, USA. All blotting reagents were purchased from Bio-Rad ${ }^{\circledR}$ (CA, USA and München, Germany) except TBST and transfer buffer, which were prepared from their components. Leptin, human, recombinant expressed in E. coli (\#L4146) was purchased from Sigma-Aldrich, $\mathrm{GmbH}$ Germany.

Breast cancer cell lines MCF-7 (p53 ${ }^{+}$and ER ${ }^{+}$), T47D (p53 mutant and $\mathrm{ER}^{+}$) and MDA-MB-231 (p53 mutant and ER') were purchased from the European Collection of Cell Cultures (ECACC, Porton Down, UK).

Cell culture. Breast cancer cell lines were grown in a continuous monolayer culture in T75 top filtered sterile tissue culture flasks inside a sterile humidified incubator at $37^{\circ} \mathrm{C}$ and $5 \% \mathrm{CO}_{2}$ in air. Cells were then sub-cultured as necessary for maintenance. Cells were used between passages 57-70, 9-22 and 12-24 for MCF-7, MDA-MB-231 and T47D cells respectively.

Western blotting. Cell lines were sub-cultured, counted and plated at $1 \times 10^{6}$ cells in appropriate tissue culture plates and incubated at $37^{\circ} \mathrm{C}$ and $5 \% \mathrm{CO}_{2}$ in a humidified atmosphere overnight. Cells were then incubated with AICAR $(0.83 \mathrm{mM})$ or with corresponding vehicle for 3 or $24 \mathrm{~h}$. Equivalent sets of cells were incubated and subjected to the same procedure with Akt inhibitor VIII in the presence or absence of AICAR for $1 \mathrm{~h}$ with corresponding controls. This was to investigate the effect of Akt inhibition on AMPK phosphorylation. To study the effect of leptin on AMPK phosphorylation, cells were incubated with AICAR \pm leptin and leptin alone. Cell lysates from control and treated cells were collected, followed by protein assay. Equal protein concentrations $(\mathrm{w} / \mathrm{v})$ of control and stimulated cells were premixed with Laemmli sample buffer (Bio-Rad) containing $\beta$-mercaptoethanol and loaded in a maximum volume of $30 \mu \mathrm{l} /$ well into wells in pre-formed Tris-HCl-SDS gels (Bio-Rad). Proteins were then separated by electrophoresis and then transferred to a PVDF membrane. The membrane was blocked overnight in $10 \%$ dry milk before being incubated overnight at $4^{\circ} \mathrm{C}$ with anti-phospho-Akt or anti-phospho-AMPK antibody, directed against p-Ser473 or p-Thr172 amino acid residues, respectively. The membrane was washed in TBST four times (15 min each) then incubated with polyclonal anti-rabbit $\operatorname{IgG}$ antibody then washed again four times before adding the horseradish peroxidase (HRP)-
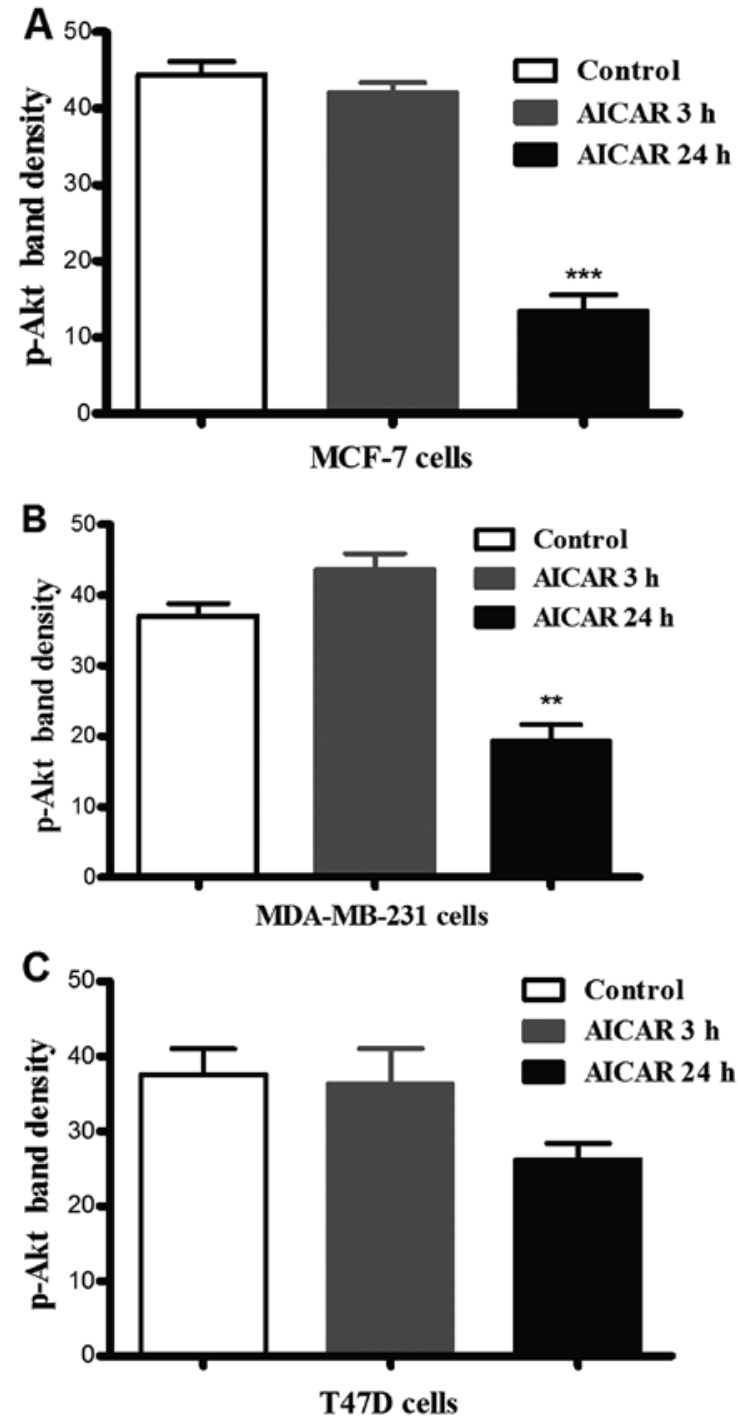

Figure 1. The effect of AICAR on Akt phosphorylation in breast cancer cells. Each of the 3 cell types were incubated with AICAR versus control (medium alone) for 3 or $24 \mathrm{~h}$ and Akt phosphorylation at Ser-473 was assessed as described in Materials and methods. Significant reduction in Akt phosphorylation was observed in MCF-7 (A) and MDA-MB-231 (B) cells, but not in T47D cells $(C){ }^{* *} \mathrm{p} \leq 0.01$ and $\left.^{* * *} \mathrm{p} \leq 0.001 ; \mathrm{n}=3\right)$.

linked substrate and generating signals that were detected on $\mathrm{X}$-ray film. Band densitometry was performed (as an equivalent percentage) using ImageJ software. Statistical analysis was investigated by Graphpad Prism.

Cell proliferation. Cells were sub-cultured, counted and plated at $7 \times 10^{3}$ cells/well in sterile 96 -well plates and incubated overnight at $37^{\circ} \mathrm{C}$ and $5 \% \mathrm{CO}_{2}$ in air. The next day, serial concentrations of AICAR $(0-16.65 \mu \mathrm{M})$, Akt inhibitor VIII alone $(0.00-4.16 \mu \mathrm{M})$ or in combination with AICAR $(0.415 \mathrm{mM})$, or leptin $(0-300 \mathrm{ng} / \mathrm{ml})$ were added. The number of viable cells was then estimated after $72 \mathrm{~h}$ using the MTS method (Aqueous One assay kit, Promega), which assesses the ability of viable cells to reduce the tetrazolium salt, 3-(4,5-dimethylthiazol-2-yl)-5-(3-carboxymethoxyphenyl)2-(4-sulfophenyl)-2H-tetrazolium (MTS), producing brownish red coloured formazan, which was measured at 490 and $630 \mathrm{~nm}$ using a Biotek ELX800 Microplate reader (Biotek 

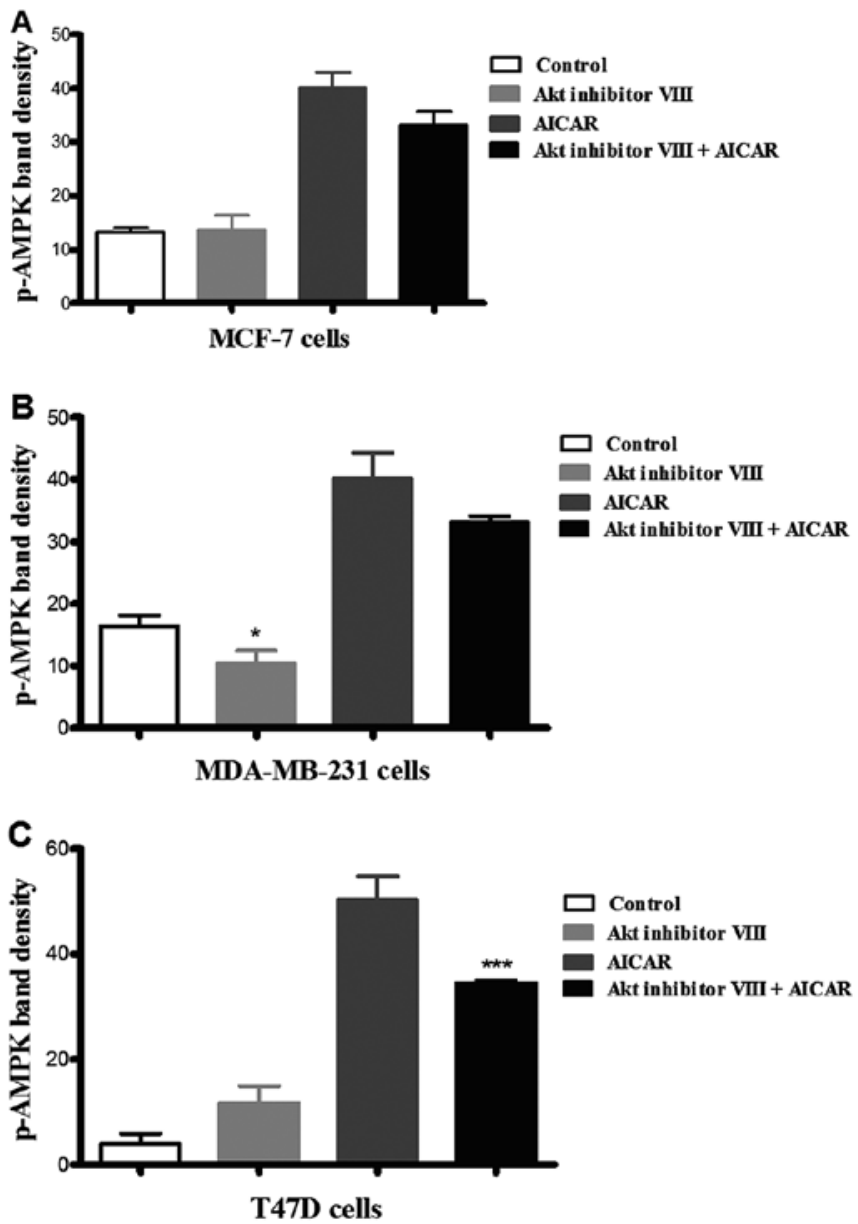

Figure 2. The effects of inhibition of Akt on AMPK phosphorylation. MCF-7, MDA-MB-231 and T47D cells were incubated with medium alone, Akt inhibitor VIII $(16.65 \mu \mathrm{M})$ alone or in the presence of AICAR $(0.415 \mathrm{mM})$. AMPK phosphorylation was assessed as described in Materials and methods. The Akt inhibitor had no effect on either basal or AICAR stimulated AMPK phosphorylation in MCF-7 cells (A) and only a small effect on basal MDAMB-231 cells (B). However, in T47D cells (C), the inhibitor significantly reduced stimulated AMPK phosphorylation $\left({ }^{*} \mathrm{p} \leq 0.05,{ }^{* * * *} \mathrm{p}<0.001 ; \mathrm{n}=3\right)$.

Instruments, Winooski, VT , USA). Cell proliferation was then calculated as percentages of control and plotted as negative dose response curves using Graphpad Prism and statistical analysis by ANOVA.

\section{Results}

We have reported previously on the significant effects of AICAR on AMPK in all three cell types (18), so to simplify presentation, we do not present statistical data on this effect alone.

Effects of AMPK activation on Akt Ser473 phosphorylation. Incubation of each of the cell lines with AICAR for 3 or $24 \mathrm{~h}$ resulted in a significant reduction in p-Akt (Ser473) levels in MCF-7 and MDA-MB-231 cells after $24 \mathrm{~h}$ as compared to the corresponding controls (there was no observable difference after $3 \mathrm{~h}$ ). In T47D cells, however, there was no significant difference in Akt phosphorylation in response to activation of AMPK at either time-point (Fig. 1).

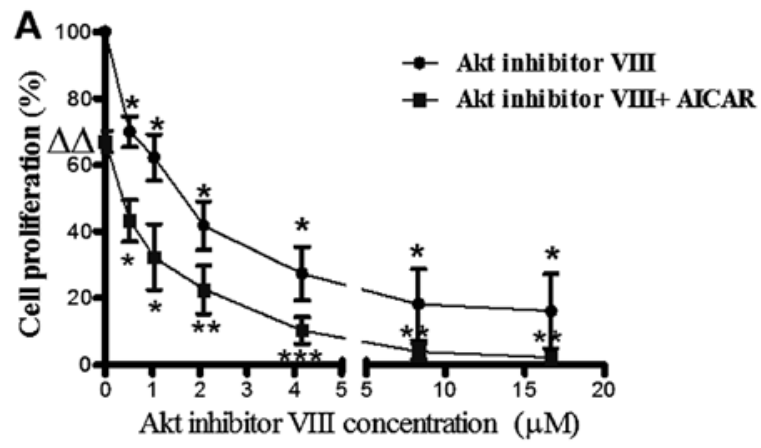

MCF-7 cells
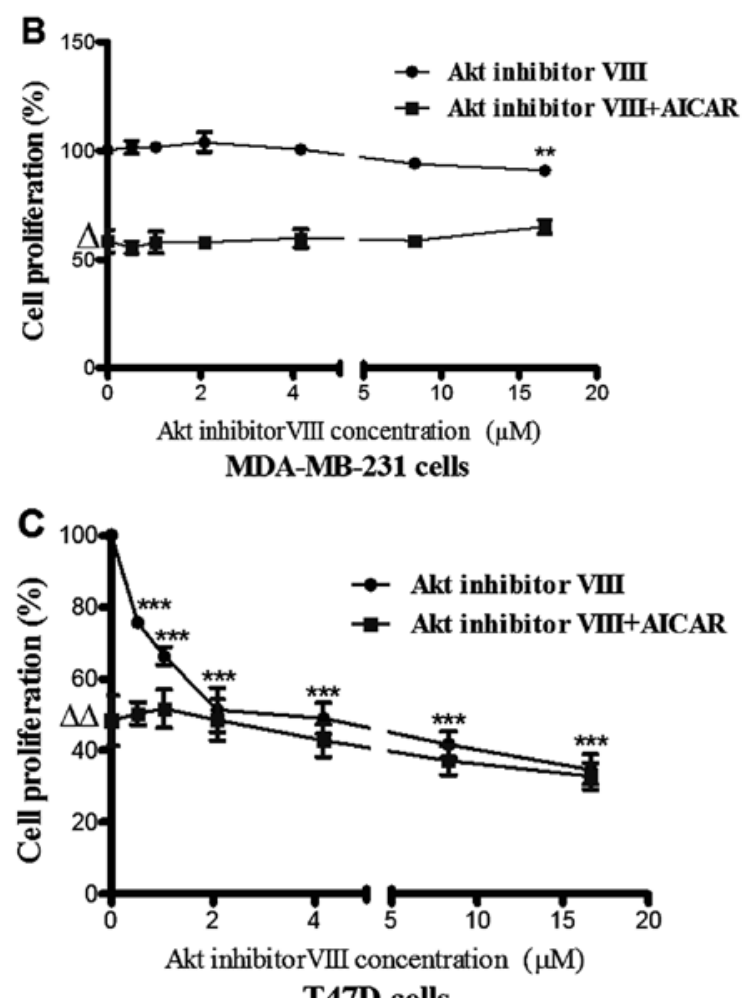

Figure 3. The effect of Akt inhibitor VIII alone and in combination with AICAR on cell proliferation. Cells were incubated with AICAR $(0.415 \mathrm{mM})$ and varying concentrations of Akt inhibitor VIII (0-16.65 $\mu \mathrm{M})$. Differential effects of Akt inhibitor VIII on cell proliferation are shown. Also shown are the effects of Akt inhibitor VIII in the presence of AICAR [ $\mathrm{k}<0.05,{ }^{*} \mathrm{p}<0.01$, ${ }^{* * *} \mathrm{p}<0.001 ; \mathrm{n}=3$ for MCF-7 (A) and MDA cells (B); $\mathrm{n}=5$ for T47D cells (C)] Triangles indicate the significance in the difference between control cell proliferation in the presence and absence of AICAR $\left({ }^{\Delta} \mathrm{p}<0.05\right.$ and $\left.{ }^{\Delta \Delta} \mathrm{p}<0.01\right)$.

Effects of inhibition of Akt on AMPK phosphorylation. Incubation of the three cell types with Akt inhibitor VIII revealed that it did not have a significant effect on AMPK phosphorylation in MCF-7 and T47D cells in comparison with the corresponding control (Fig. 2). In contrast, in MDA-MB-231 cells, treatment with Akt inhibitor VIII resulted in an apparent decrease in AMPK phosphorylation when compared to the corresponding control of medium alone. In the presence of AICAR, inhibition of Akt resulted in a significant reduction in AMPK phosphorylation in T47D cells, but did not suppress the phosphorylating effect of AICAR on AMPK in the other cell lines investigated. These results suggested that Akt inhibition increased AMPK phosphorylation in T47D cells, but not the other two cell types (Fig. 2). 

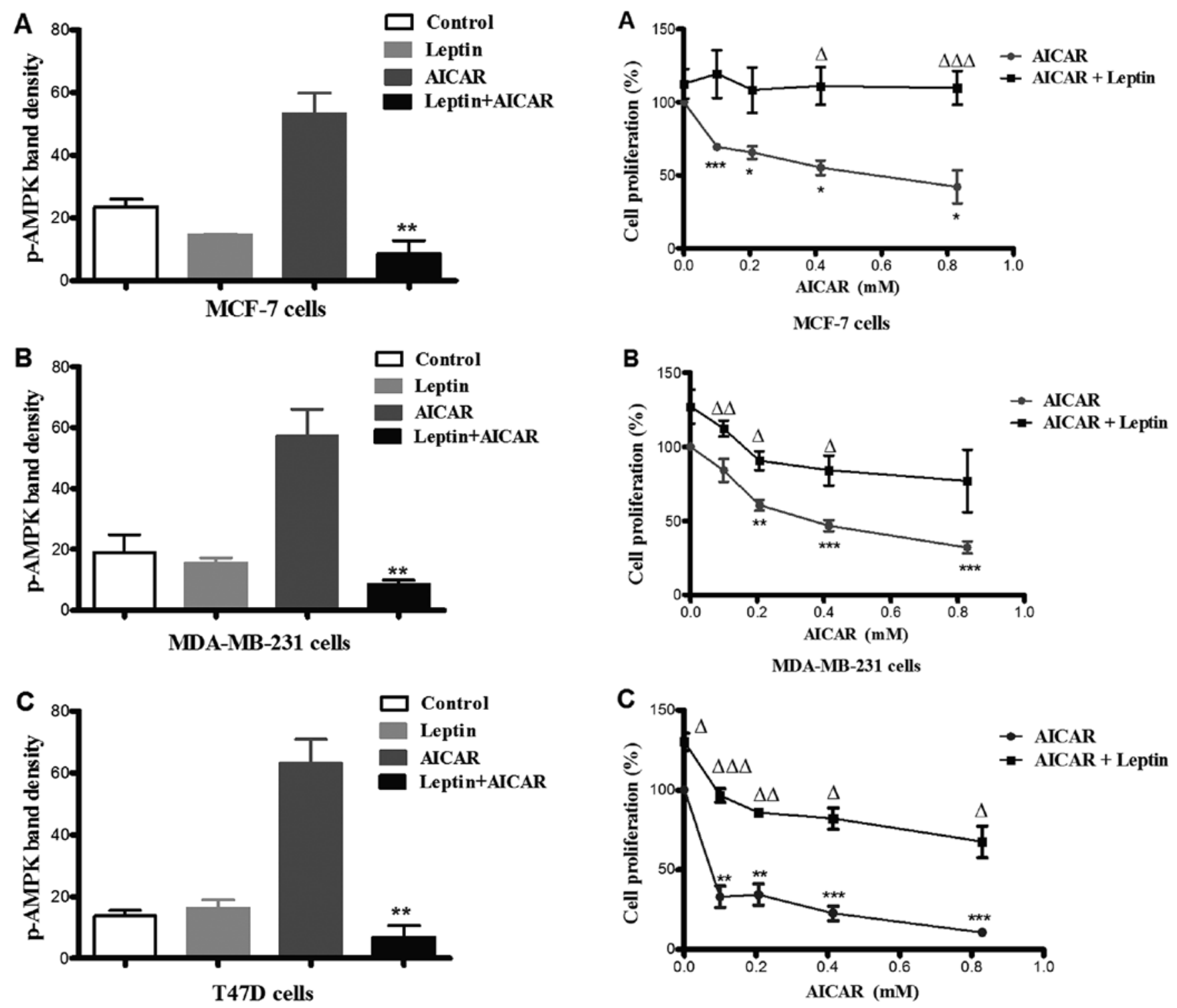

Figure 4. Co-administration of leptin with AICAR abolished its effect on AMPK phosphorylation in MCF-7 (A), MDA-MB-231 (B) and T47D (C). Cells were incubated with AICAR $(0.83 \mathrm{mM})$ in the presence or absence of leptin $(150 \mathrm{ng} / \mathrm{ml})$. The inhibitory effect of leptin on AMPK phosphorylation is shown $\left({ }^{*} \mathrm{p} \leq 0.05,{ }^{* *} \mathrm{p} \leq 0.01 ; \mathrm{n}=3\right)$.

Cell proliferation. Akt inhibition resulted in differential antiproliferative effects in the 3 breast cancer cell types.

a) MCF-7 cells. The activating effect of AICAR on AMPK was previously reported by the present group to be associated with inhibition of breast cancer cell proliferation (18). In the present study, Akt inhibitor VIII (0-16.65 $\mu \mathrm{M})$ caused a dose-dependent reduction in MCF-7 cell proliferation. Co-administration of AICAR $(0.415 \mathrm{mM})$ and Akt inhibitor VIII indicated an additive effect in this cell line (Fig. 3A).

b) MDA-MB-231 cells. The MDA-MB-231 cell line was not responsive to Akt inhibitor VIII and on combination with AICAR there was no change in the anti-proliferative action of AICAR suggesting that MDA-MB-231 cells might express an Akt isoform which is less responsive to Akt inhibitor VIII (Fig. 3B).

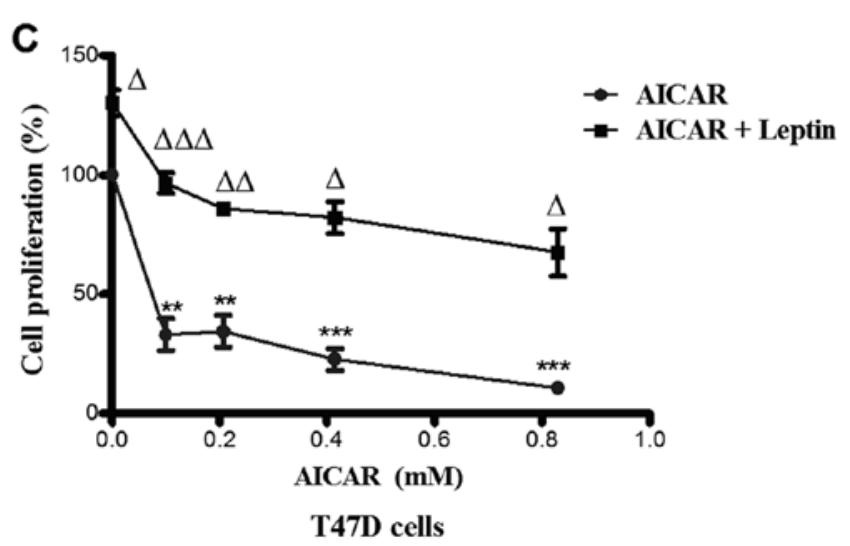

Figure 5. Effect of co-administration of leptin with AICAR on cell proliferation. Cells were incubated with AICAR $(0-0.83 \mathrm{mM})$ in the presence or absence of leptin $(150 \mathrm{ng} / \mathrm{ml})$. The effect of AICAR alone are shown ${ }^{*} \mathrm{p}<0.05,{ }^{* *} \mathrm{p}<0.01,{ }^{* * *} \mathrm{p}<0.001 ; \mathrm{n}=3$ ). The triangles show the significance of the inhibitory effects of leptin on AICAR-induced inhibition of cell proliferation $\left[{ }^{\Delta} \mathrm{p} \leq 0.05,{ }^{\triangle} \mathrm{p} \leq 0.01\right.$ and ${ }^{\triangle \triangle} \Delta \mathrm{p} \leq 0.001 ; n=3$ for MCF-7 cells (A) and $\mathrm{n}=4$ for MDA-MB-231 cells (B) and T47D cells (C)].

c) T47D cells. Although incubation of T47D cells with increasing concentrations of Akt inhibitor VIII resulted in a dose responsive inhibition of cell proliferation, co-administration of AICAR $(0.415 \mathrm{mM})$ with Akt inhibitor VIII appeared to have no influence on cell proliferation (Fig. 3C).

Leptin suppressed activated AMPK phosphorylation and cell proliferation. AICAR $(0.83 \mathrm{mM})$-induced AMPK phosphorylation was suppressed by co-administration with leptin in all three cell types. There was no evidence of a significant effect of leptin alone (Fig. 4). Leptin also differentially attenuated breast cancer cell proliferation. Indeed, the effects of leptin were also apparent at lower doses of AICAR. In MCF-7 cells, leptin abolished the effect of AMPK activation. However, in 
the other two cell types, this blockade was partial, but still significant (Fig. 5).

\section{Discussion}

Both the PI3K/Akt/mTOR and LKB/AMPK signalling pathways have been implicated in cancer (19). We have previously reported that activation of AMPK has differential effects on cell proliferation in MCF-7, MDA-MB-231 and T47D cells (18). The present study reports an investigation into the potential crosstalk between these pathways in breast cancer cell lines with differing p53 and estrogen receptor status. Activation of AMPK by AICAR exerted differential inhibitory effects on Akt phosphorylation in the three cell types investigated (Fig. 1). There was a clear inhibitory effect in MCF-7 and MDA-MB-231 cells, which was not significant in T47D cells. The inhibitory effect of AICAR on PI3K pathway components has also been reported in C6 glioma cells; a reduction in Akt phosphorylation observed both in vivo and in vitro $(20,21)$. It has also been reported that AICAR inhibited the phosphorylation of mTOR at serine 1448, a crucial event in mTOR activation (22). In contrast, in the present study, inhibition of Akt had only minimal or no significant inhibitory effects on AMPK phosphorylation in all three cell types.

There were clear differences between the cell types in response to co-administration of AICAR and Akt inhibitor VIII when cell proliferation was assessed. In MCF-7 cells, the co-administration resulted in an apparent additive inhibitory effect on cell proliferation (Fig. 3A). In MDA-MB-231 cells, however, Akt inhibitor VIII failed to produce a noticeable effect on cell proliferation (Fig. 3B) perhaps as a result of overexpression of $\mathrm{Akt} 3$ (the least responsive isoform to $\mathrm{Akt}$ inhibitor VIII) in ER-negative breast cancer cells (14). In T47D cells, simultaneous activation of AMPK by AICAR and inhibition of Akt by Akt inhibitor VIII did not produce a significant decrease in cell proliferation when compared to the effect of Akt inhibitor VIII alone (Fig. 3C). The absence of significant differences between the effects of Akt inhibitor VIII combined with AICAR might suggest that any potential additive effect of the drug combination is attenuated. This could be related to the reduction in AICAR-mediated AMPK phosphorylation upon treating cells with Akt inhibitor VIII and AICAR together (Fig. 2C).

In line with our results, another report showed that metformin-activated AMPK in MCF-7 cells resulted in de-phosphorylation of Akt, an action that helped to improve the sensitivity to anti-HER2 receptor drugs and decrease the risk of cardiomyopathy (23). It was also reported that AMPK activation downregulates the mTOR pathway in breast cancer following its activation by metformin (24).

There is growing literature linking obesity to cancer incidence (25). In this context, it was reported that leptin switches the metabolic profile of breast cancer cells from fatty acid $\beta$ oxidation to the aerobic glycolytic pathway (26). This effect was found to be accompanied by Akt activation and downregulation of the LKB1 gene with a subsequent decrease in AMPK phosphorylation (26). In the present study, treatment of MCF-7, MDA-MB-231 and T47D cells with leptin resulted in blockade of the phosphorylating effect of AICAR on AMPK (Fig. 4). This was associated with attenuation of the inhibitory effect of AMPK activation on cell proliferation in MDA-MB-231 and T47D cells and complete blockade in MCF-7 cells. In this regard, it has been reported that leptin stimulated Akt phosphorylation at Ser473 $(27,28)$ and induced PI3K-regulted PKC- $\alpha$ gene expression suggesting that leptin activates the PI3K pathway (29). A 6-fold reduction in apoptosis was observed in MCF-7 cells treated with leptin for $>24 \mathrm{~h}$ (30). This was in line with the ability of leptin to reduce the levels of p53 and Bax (31). These effects of leptin on MCF-7 cells support the concept established in the present study that leptin could oppose the antitumour effects of P-AMPK not only in this cell line but also to some extent in the other two. It has also been reported that leptin receptor is expressed on mammary cancer stem cells suggesting that leptin may act as an initiation factor for the primary mammary tumour which, once established, proliferates, migrates and invades local tissues also with the aid of leptin. Moreover, leptin could sustain angiogenesis by acting on endothelial cells to enhance the pro-inflammatory processes that are required to support tumour growth by exerting its effects on other stromal cells, such as immune cells and fibroblasts (32).

This study suggests that crosstalk between Akt and AMPK in breast cancer cells is dependent on cellular genetics. Consequently further investigation is required before deciding on the use of particular Akt inhibitors with or without an activator of AMPK. Therefore, in the context of therapeutics, administration of an Akt inhibitor with AMPK activators may be effective in some, but not all, breast cancers depending on cellular characteristics. These findings support indications that genetic profiling could be very important in defining the most effective treatment regimes across a range of therapeutic targets. Indeed, it is clear that administration of a drug targeting an intracellular process has to take account of crosstalking pathways that might interfere with treatment effectiveness. Of particular importance, from the present study, is that attempts to employ any new generation AMPK activators in the treatment of breast cancer could be less effective in patients with high circulating levels of leptin, again dependent on the genetic background of the tumour.

\section{Acknowledgements}

We wish to thank The Egyptian Cultural Agency for part funding. We also thank Professor David Hornby for his generosity in accommodating part of this project in the Department of Molecular Biology and Biotechnology. We are grateful to Drs Janice Royds and Stuart Johnson for useful discussions.

\section{References}

1. Hardie DG: The AMP-activated protein kinase pathway - new players upstream and downstream. J Cell Sci 117: 5479-5487, 2004.

2. Lizcano JM, Göransson O, Toth R, Deak M, Morrice NA, Boudeau J, Hawley SA, Udd L, Mäkelä TP, Hardie DG, et al: LKB1 is a master kinase that activates 13 kinases of the AMPK subfamily, including MARK/PAR-1. EMBO J 23: 833-843, 2004.

3. Lawlor MA and Alessi DR: PKB/Akt: A key mediator of cell proliferation, survival and insulin responses? J Cell Sci 114: 2903-2910, 2001.

4. Calleja V, Laguerre M, Parker PJ and Larijani B: Role of a novel $\mathrm{PH}-$ kinase domain interface in $\mathrm{PKB} / \mathrm{Akt}$ regulation: structural mechanism for allosteric inhibition. PLoS Biol 7: e17, 2009. 
5. Calleja V,Alcor D,Laguerre M,Park J, Vojnovic B, Hemmings BA, Downward J, Parker PJ and Larijani B: Intramolecular and intermolecular interactions of protein kinase B define its activation in vivo. PLoS Biol 5: e95, 2007.

6. Calleja V, Laguerre M and Larijani B: 3-D structure and dynamics of protein kinase B-new mechanism for the allosteric regulation of an AGC kinase. J Chem Biol 2: 11-25, 2009.

7. Staal SP: Molecular cloning of the akt oncogene and its human homologues AKT1 and AKT2: Amplification of AKT1 in a primary human gastric adenocarcinoma. Proc Natl Acad Sci USA 84: 5034-5037, 1987.

8. Cheng JQ, Godwin AK, Bellacosa A, Taguchi T, Franke TF, Hamilton TC, Tsichlis PN and Testa JR: AKT2, a putative oncogene encoding a member of a subfamily of protein-serine/ threonine kinases, is amplified in human ovarian carcinomas. Proc Natl Acad Sci USA 89: 9267-9271, 1992.

9. Cheng JQ, Ruggeri B, Klein WM, Sonoda G, Altomare DA, Watson DK and Testa JR: Amplification of AKT2 in human pancreatic cells and inhibition of AKT2 expression and tumorigenicity by antisense RNA. Proc Natl Acad Sci USA 93: 3636-3641, 1996.

10. Stahl JM, Sharma A, Cheung M, Zimmerman M, Cheng JQ, Bosenberg MW, Kester M, Sandirasegarane L and Robertson GP: Deregulated Akt3 activity promotes development of malignant melanoma. Cancer Res 64: 7002-7010, 2004.

11. Stål O, Pérez-Tenorio G, Akerberg L, Olsson B, Nordenskjöld B Skoog L and Rutqvist LE: Akt kinases in breast cancer and the results of adjuvant therapy. Breast Cancer Res 5: R37-R44, 2003.

12. Xu X, Sakon M, Nagano H, Hiraoka N, Yamamoto H, Hayashi N, Dono K, Nakamori S, Umeshita K, Ito Y, et al: Akt2 expression correlates with prognosis of human hepatocellular carcinoma. Oncol Rep 11: 25-32, 2004.

13. Roy HK, Olusola BF, Clemens DL, Karolski WJ, Ratashak A, Lynch HT and Smyrk TC: AKT proto-oncogene overexpression is an early event during sporadic colon carcinogenesis. Carcinogenesis 23: 201-205, 2002.

14. Nakatani K, Thompson DA, Barthel A, Sakaue H, Liu W, Weigel RJ and Roth RA: Up-regulation of Akt3 in estrogen receptor-deficient breast cancers and androgen-independent prostate cancer lines. J Biol Chem 274: 21528-21532, 1999.

15. Houseknecht KL and Spurlock ME: Leptin regulation of lipid homeostasis: dietary and metabolic implications. Nutr Res Rev 16: 83-96, 2003

16. Myers MG Jr: Leptin receptor signaling and the regulation of mammalian physiology. Recent Prog Horm Res 59: 287-304, 2004.

17. Cirillo D, Rachiglio AM, la Montagna R, Giordano A and Normanno N: Leptin signaling in breast cancer: An overview. J Cell Biochem 105: 956-964, 2008
18. El-Masry OS, Brown BL and Dobson PR: Effects of activation of AMPK on human breast cancer cell lines with different genetic backgrounds. Oncol Lett 3: 224-228, 2012.

19. Hardie DG and Alessi DR: LKB1 and AMPK and the cancermetabolism link - ten years after. BMC Biol 11: 36, 2013.

20. Brazil DP, Yang ZZ and Hemmings BA: Advances in protein kinase B signalling: AKTion on multiple fronts. Trends Biochem Sci 29: 233-242, 2004.

21. Rattan R, Giri S, Singh AK and Singh I: 5-Aminoimidazole4-carboxamide-1-beta-D-ribofuranoside inhibits cancer cell proliferation in vitro and in vivo via AMP-activated protein kinase. J Biol Chem 280: 39582-39593, 2005.

22. Kimball SR: Interaction between the AMP-activated protein kinase and mTOR signaling pathways. Med Sci Sports Exerc 38: 1958-1964, 2006.

23. Vazquez-Martin A, Oliveras-Ferraros C, del Barco S, MartinCastillo B and Menendez JA: The antidiabetic drug metformin: a pharmaceutical AMPK activator to overcome breast cancer resistance to HER 2 inhibitors while decreasing risk of cardiomyopathy. Ann Oncol 20: 592-595, 2009.

24. Hadad SM, Fleming S and Thompson AM: Targeting AMPK: a new therapeutic opportunity in breast cancer. Crit Rev Oncol Hematol 67: 1-7, 2008

25. Sundaram S, Johnson AR and Makowski L: Obesity, metabolism and the microenvironment: Links to cancer. J Carcinog 12: 19 , 2013.

26. Ando $S$ and Catalano S: The multifactorial role of leptin in driving the breast cancer microenvironment. Nat Rev Endocrinol 8: 263-275, 2011

27. Frankenberry KA, Skinner H, Somasundar P, McFadden DW and Vona-Davis LC: Leptin receptor expression and cell signaling in breast cancer. Int J Oncol 28: 985-993, 2006.

28. Garofalo C and Surmacz E: Leptin and cancer. J Cell Physiol 207: 12-22, 2006.

29. Okumura M, Yamamoto M, Sakuma H, Kojima T, Maruyama T, Jamali M, Cooper DR and Yasuda K: Leptin and high glucose stimulate cell proliferation in MCF-7 human breast cancer cells: reciprocal involvement of PKC-alpha and PPAR expression. Biochim Biophys Acta 1592: 107-116, 2002.

30. Perera CN, Spalding HS, Mohammed SI and Camarillo IG: Identification of proteins secreted from leptin stimulated MCF-7 breast cancer cells: A dual proteomic approach. Exp Biol Med (Maywood) 233: 708-720, 2008.

31. Nkhata KJ, Ray A, Schuster TF, Grossmann ME and Cleary MP: Effects of adiponectin and leptin co-treatment on human breast cancer cell growth. Oncol Rep 21: 1611-1619, 2009.

32. Park J and Scherer PE: Leptin and cancer: From cancer stem cells to metastasis. Endocr Relat Cancer 18: C25-C29, 2011 